EGU2020-4742

https://doi.org/10.5194/egusphere-egu2020-4742

EGU General Assembly 2020

(c) Author(s) 2020. This work is distributed under

the Creative Commons Attribution 4.0 License.

\title{
Integration of bedrock, seismic tomographic and plate kinematic constraints to test models of the India-Asia collision
}

\author{
Andrew Parsons, Kasra Hosseini, Richard Palin, and Karin Sigloch \\ University of Oxford, Department of Earth Sciences, Oxford, UK (andrew.parsons@earth.ox.ac.uk)
}

The India-Asia collision is one of the most well-studied orogenic events on Earth; it recorded the terminal stages of the central Tethys ocean basins and offers invaluable insight into the geological processes associated with continental collision. In this study, we integrate bedrock datasets, observations of subducted slabs in the mantle, and plate kinematic constraints, to constrain models for the India-Asia collision and the central Tethys oceans.

Previously proposed models for the India-Asia collision differ in terms of subduction zone configurations and paleogeographic reconstructions of Greater India, which represents to northern passive margin of India prior to collision. Five distinct subduction zone configurations have been proposed previously, which differ in the number of active trenches (one or two trenches) in the central Neotethys Ocean and differ in the respective timing, duration, location and migration of those trenches. Three distinct paleogeographic reconstructions of Greater India have been proposed previously, which differ in size and structure. Here, we consider the validity of these subduction zone configurations and Greater India reconstructions with respect to the bedrock record, plate kinematics and the deep mantle structure of subducted slabs beneath the Indian hemisphere.

Following the assumption that slabs sink vertically through the mantle, the positions and geometries of subducted slabs determined from seismic tomography constrain the locations and kinematics of paleo-subduction zones. Integrating this with bedrock constraints allows us to constrain post-Triassic subduction zone configurations for the central Tethys oceans. Our analysis demonstrates that the Neotethys Ocean was consumed by at least two subduction zones since the Jurassic. At the onset of the India-Asia collision at $59 \pm 1 \mathrm{Ma}$, one subduction zone was active along the southern Asian continental margin at $\sim 20^{\circ} \mathrm{N}$. At that time, a second may have been active at subequatorial latitudes, but support for this from a bedrock perspective is lacking. This subduction zone configuration allows for three reconstructions for Greater India: The (1) minimum-area; (2) enlarged-area; and (3) Greater India Basin reconstructions. We integrate these reconstructions and subduction zone configurations in a plate kinematic framework to test their validity for the IndiaAsia collision.

Our findings show that no single model is entirely satisfactory and each invokes assumptions that challenge accepted concepts. These include our understanding of suture zones, subductionerosion processes, and the limits of continental subduction. We explore these challenges and their 
implications for our understanding of the India-Asia collision and continental collisions in general. 